\title{
A construção de um grafite digital coletivo como um recurso pedagógico em tempos de confinamento
}

\author{
The construction of a collective digital graffiti as a pedagogical resource in times of \\ confinement
}

Joy Helena Worms Till, Rita Maria de Souza Couto, Julianna de Carvalho Lemos

ensino remoto, metodologia colaborativa, interação, confinamento, ambiente virtual

Este documento apresenta o desenvolvimento de uma experiência pedagógica com alunos da graduação em Design da PUC-Rio, realizada durante o período de ensino remoto imposto pela emergência sanitária em consequência da pandemia da COVID-19. Está estruturado em quatro tópicos, iniciando-se com uma análise da mudança repentina do ensino para o espaço virtual, seguida de um breve relato acerca da estrutura e metodologia da disciplina. Isso posto, são apresentados os desafios e as soluções encontradas para a realização de uma ação colaborativa num contexto inteiramente digital, evidenciando, assim, o processo da construção da proposta de interação e da descrição do grafite digital coletivo realizado ao final do semestre. Encerramos com algumas reflexões sobre a experiência realizada e a potencialidade do ambiente virtual, que, em uma condição posterior ao período de confinamento, poderão ser somadas aos recursos pedagógicos presenciais.

remote teaching, collaborative methodology, interaction, confinement, virtual environment

This document presents the development of a pedagogical experience with undergraduate design students at PUC-Rio, that took place during the remote teaching period imposed by the health emergency of the COVID19 pandemic. It is structured in four topics, starting with an analysis of the abrupt shift from classroom to virtual teaching, followed by a brief account of the structure and methodology of the discipline in which the collaborative action project took place, showing the process of building the interaction proposal and the description of the collective digital graffiti carried out by the end of the semester. We end with some reflections on the experience and the potential of the virtual environment, when added to the classroom teaching resources, in a future situation after the confinement period.

\section{Introdução}

Em março de 2020, o sistema educacional precisou enfrentar, com a situação imposta pela pandemia do COVID-19, momentos de mudanças radicais na forma como oferecia seus serviços à sociedade.

$\mathrm{Na}$ impossibilidade de manter o modelo presencial de atividades, todo o sistema educacional foi afetado, em maior ou menor escala. Assim, desde a suspensão completa de atividades, a busca de alternativas para instaurar modelos de ensino remoto foram

Anais do $10^{\circ} \mathrm{CIDI}$ e $10^{\circ} \mathrm{CONGIC}$

Kelli C.A.S. Smythe, Rafael de Castro Andrade (orgs.)

Sociedade Brasileira de Design da Informação - SBDI

Curitiba | Brasil | 2021
Proceedings of the $10^{\text {th }} \mathrm{CIDI}$ and $10^{\text {th }}$ CONGIC

Kelli C.A.S. Smythe, Rafael de Castro Andrade (orgs.)

Sociedade Brasileira de Design da Informação - SBDI Curitiba | Brazil | 2021 
necessárias, frente ao quadro de perplexidade e dúvidas que se apresentou e que, infelizmente, tem se estendido por mais tempo do que o esperado inicialmente.

Em um país das dimensões do nosso e de severa desigualdade social, infelizmente vários alunos com vulnerabilidade social foram e ainda têm sido privados de seu direito fundamental à educação, muito em função da impossibilidade de acesso a recursos tecnológicos que permitiriam viabilizar, de forma remota, a continuidade de sua formação.

A experiência apresentada neste artigo não desconhece o problema acima contemplado, e que, por certo, deveria estar na ordem do dia das discussões sobre o futuro de nossa juventude. Negar o uso aos alunos dos artefatos tecnológicos por questões de vulnerabilidade social é desconhecer suas possibilidades e uma posição de derrota e desalento. A devida discussão crítica não nos levará a resolver os problemas que emergem neste contexto novo para a escola, contudo, a educação em nosso país precisa ser criticamente preparada para o novo cenário que se descortina neste momento de crise, mas, também, de oportunidades.

Uma vez apresentada a posição dos autores em relação ao quadro atual que a todos atinge, iniciamos uma breve reflexão sobre a questão das tecnologias no ambiente de sala de aula, como forma de introduzir o relato de uma experiência acadêmica realizada no contexto contemporâneo da pandemia, marcado pelo confinamento e pela intensa vivência no ambiente digital. Neste sentido, podemos abrir novas possibilidades de entendimento sobre os itinerários transversais percorridos, os quais, longe de serem modelos apenas para a situação de emergência ou para um público agraciado pela sorte de poder contar com o acesso ao ensino remoto, precisam ser pensados para atingir vários pontos do país, ampliando o acesso a um ensino de qualidade. Segundo Moran (2002), o processo de ensinar e aprender não deve ficar restrito ao ambiente de sala de aula, pois ele requer do docente a modificação continuada do que faz dentro e fora dela, tanto no presencial quanto no virtual.

O contexto tecnológico em que vivemos tem solicitado, cada vez mais, uma sala de aula interativa e, neste particular, tem exigido do professor competências dinâmicas e um perfil docente diferenciado para acompanhar o ritmo acelerado que as tecnologias proporcionam. Para Perrenoud (2000), deste modo, as novas tecnologias não deveriam ser indiferentes a nenhum professor, uma vez que modificam seu modo de ser e estar no mundo, afetando seus modos de viver, de se divertir, de se informar, de trabalhar e de pensar. Tal evolução afeta, portanto, as situações que os alunos enfrentam e enfrentarão, nas quais eles pretensamente mobilizam e mobilizarão o que aprenderam na escola.

As ideias de Perrenoud delineiam um quadro presente em muitos contextos educacionais brasileiros, pois nem sempre a fluência digital do professor permitiu usufruir plenamente dos inúmeros recursos digitais. Contudo, mesmo considerando que com o advento da pandemia este problema se mostrou crítico para muitos, trouxe também muitas oportunidades de ações pedagógicas criativas.

Apesar de ainda não termos acessibilidade para todos, há algumas décadas as tecnologias digitais e, em especial, a conexão à internet, potencializam a comunicação e nos aproximam de um excepcional conjunto de informações. Entre pesquisas e navegações não lineares, 
clicamos em links, nos movemos pelos nós da rede, entramos e saímos de universos variados, em inúmeras ações possíveis. De acordo com as múltiplas interações, cada um de nós articula as informações acionadas de modo diferente, conforme interesses e associações particulares. Não somos mais receptores estáticos de informações fechadas, somos interatores ${ }^{1}$. A partir das nossas ações nos tornamos também emissores, co-autores ativos na produção da comunicação. Como observa Silva (2001), a "disposição interativa" traz aos usuários a possibilidade de atuarem como co-criadores, participando em ações, controlando acontecimentos e alterando conteúdos, transpondo o papel de espectadores passivos para o de sujeitos operativos.

Nesse sentido, na sala de aula interativa, o professor assume um papel de mediador, não mais um exclusivo emissor de informações para um conjunto passivo de alunos. Para Silva, o professor "constrói um conjunto de territórios a explorar". (...) Ele propõe o conhecimento. Não o transmite." Não oferece uma rota definida mas se torna um provocador de questionamentos, gerando problemas a serem investigados e assumindo um papel de coordenação de equipes e sistematização de experiências.

A experiência relatada a seguir traz uma contribuição sobre nossa atuação como geradores de questionamentos e reflexões, por meio de uma atividade pedagógica interativa. Realizada em um período de restrição total aos contatos presenciais e ao campus, teve - no ambiente virtual - toda a sua idealização, desenvolvimento e execução, produzida colaborativamente pela turma.

\section{A mudança repentina para o ensino remoto}

O ano de 2020 caracterizou-se pela necessidade de nos familiarizarmos com a inesperada condição de quarentena e todas as significativas alterações que esta trouxe consigo, seja nos modos de morar, conviver, estudar, trabalhar ou em tantas outras consequências imediatas. Em nossa universidade, em função da necessidade de oferecer aos alunos a efetiva continuidade do seu desenvolvimento acadêmico, desde a abrupta interrupção das aulas presenciais, a partir de 16/03, buscamos e aprendemos uma série de ferramentas e ambientes de aprendizagem on-line, rumo ao ensino remoto. Nossas salas de aula foram transferidas para um campus virtual, no qual a interação - entre docente e discente e entre os alunos -, passou a nos exigir comportamentos e práticas, senão desconhecidas, nada rotineiras.

Com exceção da facilidade com o ambiente de aprendizagem Google Classroom ${ }^{2}$ - já utilizado há alguns semestres em nosso departamento, para comunicação com os alunos e/ou

\footnotetext{
${ }^{1}$ Interator é o termo utilizado por Arlindo Machado para definir o sujeito que atua como receptor ativo e imerso diante dos projetos apresentados nas novas mídias, onde a narrativa é construída através de suas intervenções, conforme as possibilidades que tenham sido dadas pelo sistema. $O$ interator não apenas recebe informações, mas através de suas ações desencadeia os acontecimentos, num processo dialógico. (Machado: 2001, acesso em: 23 jul. 2021)

${ }^{2}$ Google Classroom é um ambiente virtual de aprendizagem da empresa Google, cujo objetivo é permitir a professores, alunos e instituições de ensino um espaço de gerenciamento de conteúdo. Possibilita também uma ótima integração com outras ferramentas oferecidas pela empresa. <https://classroom.google.com>
} 
publicação de tarefas e atividades de avaliação -, a imposição do ensino remoto nos exigiu um grande mergulho no espaço virtual.

Mantivemos os horários de aula, respeitando a grade em que os alunos se matricularam, porém as condições de acesso à tecnologia de nossos alunos são muito diversas, seja em relação à conexão com a internet ou a computadores e equipamentos, que, se presentes no campus universitário, tornaram-se de impossível utilização. A universidade buscou emprestar equipamentos para os alunos que apresentaram estas necessidades, minorando dificuldades. Ainda assim, o acesso à internet era oferecido com o mínimo de qualidade, ou o aluno tinha condições em sua residência para conectar-se a tempo. Desse modo, tivemos que trabalhar com ferramentas que nos possibilitaram realizar atividades síncronas e assíncronas.

Isso posto, a aula permanece em tempo real, porém os alunos que não têm como acompanhá-la, podem acessar seu conteúdo por meio do registro audiovisual nos serviços de videoconferência e disponibilizados, caso necessários. Para transpor o espaço da sala de aula, utilizamos as ferramentas $\mathrm{Meet}^{3}$ e Zoom ${ }^{4}$, ambas de fácil utilização, com recursos de vídeo, gravação, compartilhamento de tela, chat, entre outros.

Indo além, exploramos diversas ferramentas de interação, como mapas de ideias, diagramas e gráficos etc, que nos permitiram a ampliação das dinâmicas simultâneas. Dentre as atividades realizadas coletivamente durante os encontros remotos síncronos, a utilização da plataforma virtual Miro ${ }^{5}$ e da rede social Discord ${ }^{6}$ proporcionou espaços de comunicação e interação de forma assíncrona, ampliando o ambiente da sala de aula.

\section{A estrutura da disciplina}

A ação pedagógica que descrevemos a seguir sucedeu-se na disciplina Questões de Mobilidade e Ubiquidade, da graduação em Design na PUC-Rio, no segundo semestre de 2020. Oferecida anualmente, tem entre seus objetivos: apresentar os conceitos de mobilidade e ubiquidade computacional e sua inserção no cotidiano; desenvolver no aluno uma postura reflexiva em relação às possibilidades de utilização da tecnologia computacional na sociedade contemporânea e incentivar o desenvolvimento de trabalhos inovadores em dispositivos móveis, que contribuam para o enriquecimento da área.

Essa disciplina tem como um dos principais marcos teóricos o pensamento de Pierre Lévy, em seu conceito de "inteligência coletiva (IC)", o qual define como compartilhamento de

\footnotetext{
${ }^{3}$ Meet é mais uma ferramenta do Google, lançada em 2017 e definida como um serviço de comunicação por vídeo, permitindo também o uso de chat, áudio e compartilhamento de tela pelos usuários. <https://meet.google.com>

${ }^{4}$ O Zoom, da Zoom Video Communications, é de 2011 e se apresenta como uma solução para reuniões on-line, também permitindo o uso de vídeo, áudio, chat, porém com mais recursos para trabalhos colaborativos. $<$ https://zoom.us/about>

${ }^{5}$ Miro é uma plataforma colaborativa remota, com inúmeros recursos de pensamento gráfico como mapas mentais, organogramas, fluxogramas, jornadas de usuário entre outras. <https://miro.com/about/>

${ }^{6}$ O Discord, surgido em 2015 para comunicação entre jogadores on-line, é um serviço que oferece interfaces de voz, vídeo e texto, com a intenção de reunir pessoas e comunidades, simplificando a conversa informal e troca de ideias entre seus usuários. <https://discord.com/company>
} 
funções cognitivas, como a memória, a percepção e o aprendizado. Para o autor, cada vez que o ser humano organiza ou reorganiza sua relação consigo mesmo, com seus semelhantes, com as coisas, com os signos, com o cosmo, ele se envolve em uma atividade de conhecimento, de aprendizado." (Lévy, 2003, p. 121) O autor também observa o quanto a IC é especialmente potencializada pelas conexões tecnológicas inseridas em nossas vidas, em ambientes de troca e interação entre seus participantes.

Desse modo, iniciamos cada semestre com leituras de textos e seminários em torno de tecnologia, mobilidade, design e arte, especialmente no universo digital. Em seguida, a partir das preocupações em torno das questões digitais contemporâneas, trazidas pelos alunos, alguns temas se destacam e culminam na pesquisa aprofundada e posterior alimentação de uma linha do tempo coletiva, disponibilizada on-line.

Como esta atividade é produzida em plataformas virtuais, referenciada a partir de fontes disponíveis na internet, não chegamos a observar nenhuma interferência significativa em função do ensino remoto, tendo sido cumprido o objetivo de articular temas contemporâneos relevantes para o grupo, através da sua evolução histórica. Esta dinâmica busca também fazer com que a turma se conheça, identifique afinidades temáticas, motivações e habilidades comuns etc, questão que neste semestre se tornou ainda mais importante, considerando a ausência da convivência no campus e em sala.

A partir dos seminários, aprofundamento dos temas e das consequentes reflexões realizadas na primeira metade do período, seguimos para - em tempos presenciais - 0 desenvolvimento de um projeto de ação no espaço físico, articulando design, dispositivos móveis e interação com o público. Em etapas de conceituação, pré-produção, produção, evento em si e pós-produção, uma equipe única da turma é responsável também por sua respectiva documentação e divulgação para a comunidade PUC-Rio. Para que se torne possível, a equipe é subdividida para o desenvolvimento de tarefas específicas, conforme as competências e habilidades de cada um, numa construção interdisciplinar.

Com esta dinâmica, é proposto a cada aluno o compartilhamento de seus conhecimentos técnicos, a abertura para o aprendizado colaborativo e a disponibilidade para atuar nas diversas frentes necessárias ao desenvolvimento da ação, levando os alunos a perceber a importância da sua contribuição no objeto coletivo.

No segundo semestre de 2020.2, surge o desafio de repensar o projeto para a condição online. Como adequar o desenvolvimento colaborativo e, especialmente, a interação presencial? Como trazer a participação do público para o espaço virtual? Questões essenciais a serem resolvidas sem a vivência prévia, nem pelos alunos nem pelos professores.

\section{A construção da ação}

Antes da situação restritiva da pandemia, as diversas turmas de Questões de Mobilidade e Ubiquidade produziram e realizaram intervenções presenciais, cujo objetivo era criar conexões entre os espaços físicos e virtuais. Essas ações, de modo geral, aconteciam durante as 
Semanas de Design, evento produzido pelo nosso departamento, no campus da universidade. Para a turma deste semestre, qualquer proposta deveria responder à imposição da concepção, desenvolvimento, produção e realização exclusivamente no universo virtual.

Como comentado anteriormente, o projeto é produzido pela turma como um todo e estruturado em etapas, revistas e renovadas a cada encontro semanal. Após a pré-produção, na qual definimos o tema e a conceituação da atividade, construímos a metodologia de produção, estabelecendo equipes menores, para permitir o aprofundamento das diversas frentes de trabalho, dedicadas ao desenvolvimento da ação em si, à documentação do processo e à sua divulgação.

Durante as aulas da disciplina, por diversas vezes utilizamos o recurso de distribuição de salas, fornecido pela ferramenta Zoom, para que pudéssemos potencializar as ideias da turma e aproximar os alunos, ainda que à distância. Enquanto os grupos trabalhavam, registravam suas propostas no ambiente Miro, em um painel (board) único de modo que todos pudessem discutir e construir caminhos comuns. Este espaço nos permitiu adaptar uma dinâmica muito adotada nas aulas presenciais, como se estivéssemos debruçados sobre uma folha de papel coletiva, na qual todos intervêm e a alimentam. Porém, no ambiente digital, a "folha de papel" se transforma em algo contínuo, permanecendo disponível e editável, seja síncrona, ou assincronamente, viabilizando contribuições a todo momento.

Figura 1: Articulações produzidas durante as aulas na plataforma Miro. Fonte: acervo dos autores.

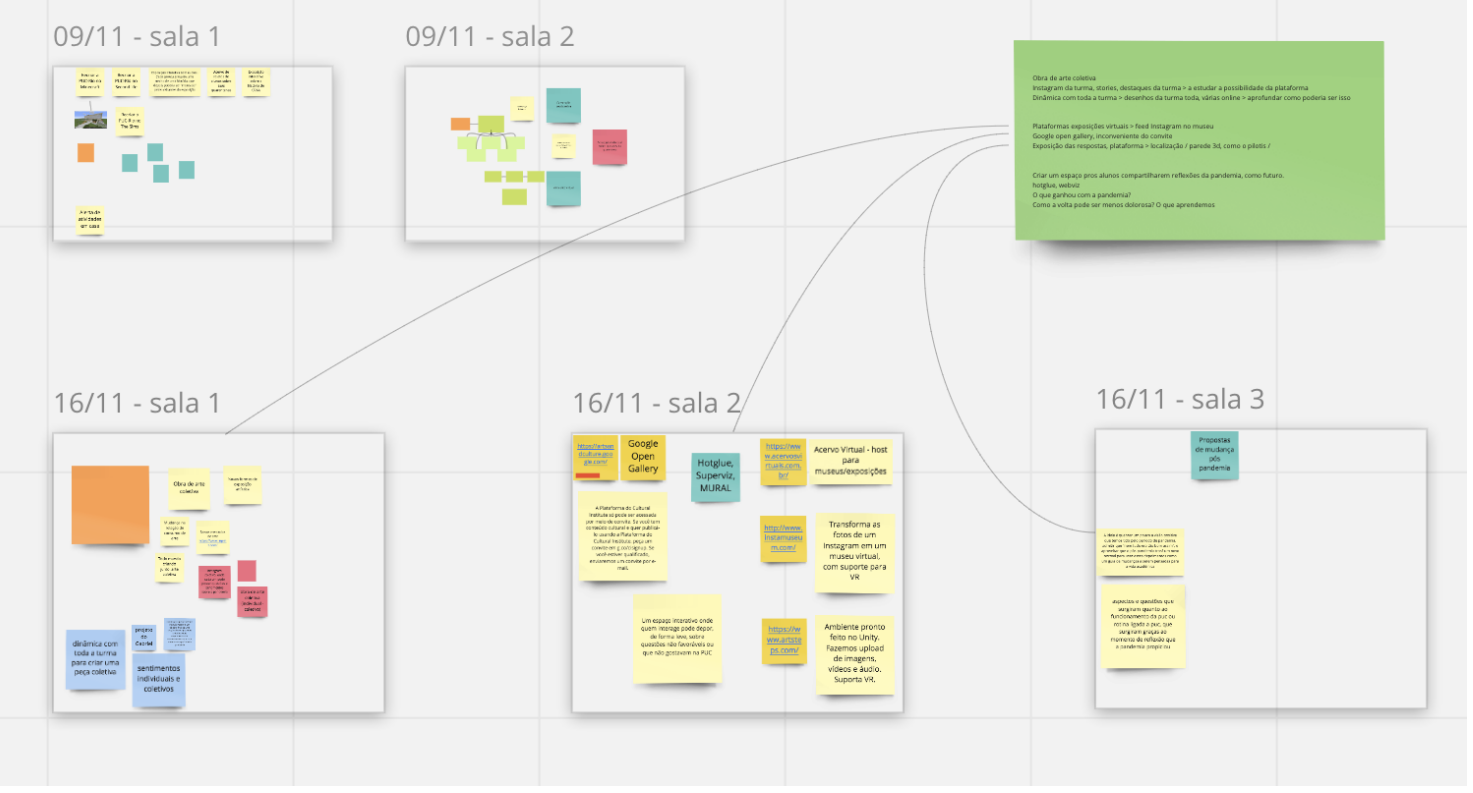

Pela dificuldade de conexão de alguns alunos, eventualmente dificultando sua participação no encontro semanal, o painel no Miro configurou-se também como elemento facilitador das articulações fora do horário de aula. Por ali tornou-se possível para os alunos acompanharem o que tinha sido encaminhado em sala de aula e acrescentarem sua contribuição. 
Figura 2: Proposta inicial começando a tomar forma, produzida durante uma das aulas no ambiente do Miro. Fonte: acervo dos autores.

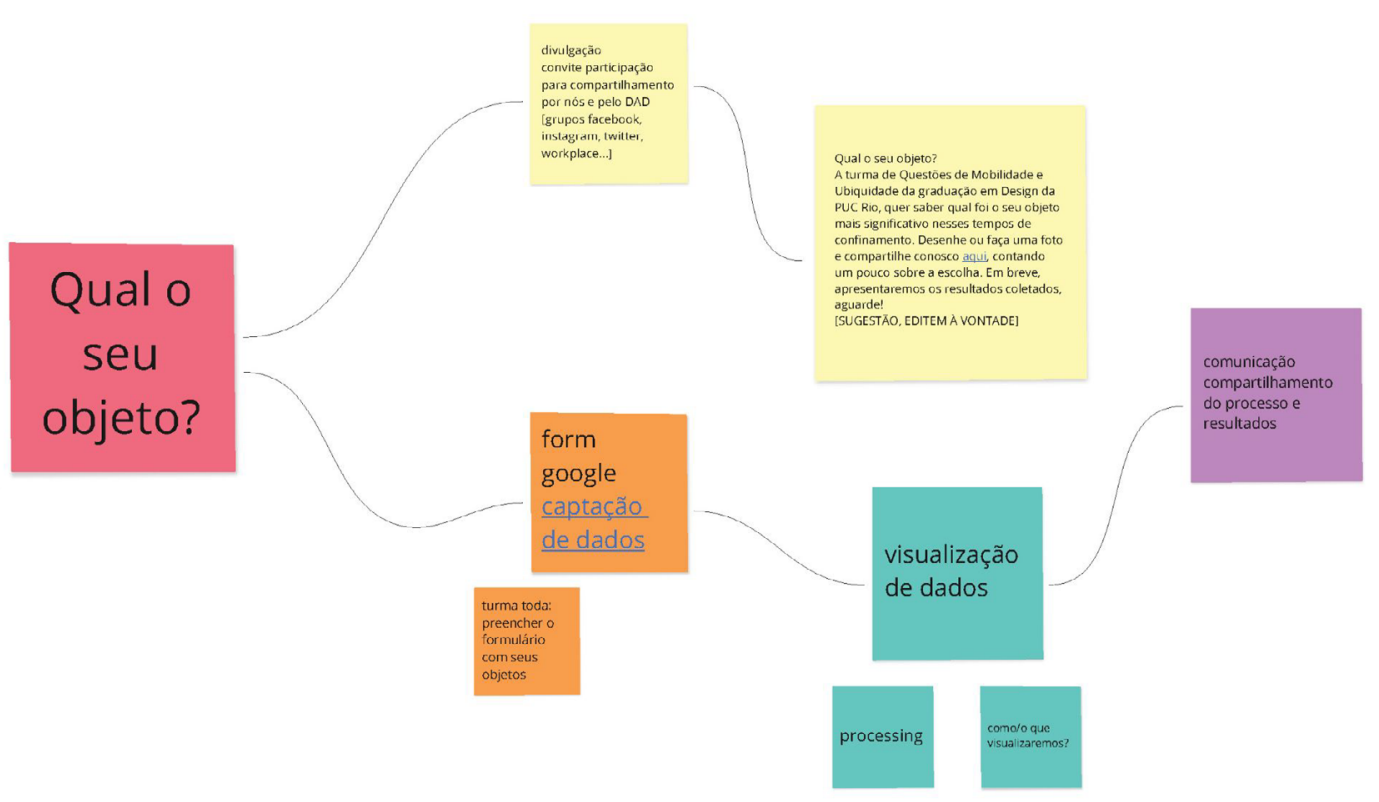

No entanto, ainda precisávamos de um ponto de encontro virtual, no qual pudéssemos reforçar a distribuição de tarefas da semana, esclarecer dúvidas sobre o desenvolvimento de cada frente de trabalho, assim como outras atividades. O software Discord, disponível em celulares e computadores, já utilizado em nosso departamento, foi a opção para articulação entre as equipes e toda a turma. Nele, dentre algumas das suas funções, é possível criar espaços de conversas por voz, texto, assim como compartilhar links. Criamos um servidor para a turma e, no sistema compartilhado, organizamos estudos das plataformas possíveis para os diversos momentos da ação, definimos as artes finais para divulgação nas redes sociais, entre outras decisões projetuais e de desenvolvimento. 
Figura 2: Interface do espaço de discussão da turma no Discord. Fonte: acervo dos autores.

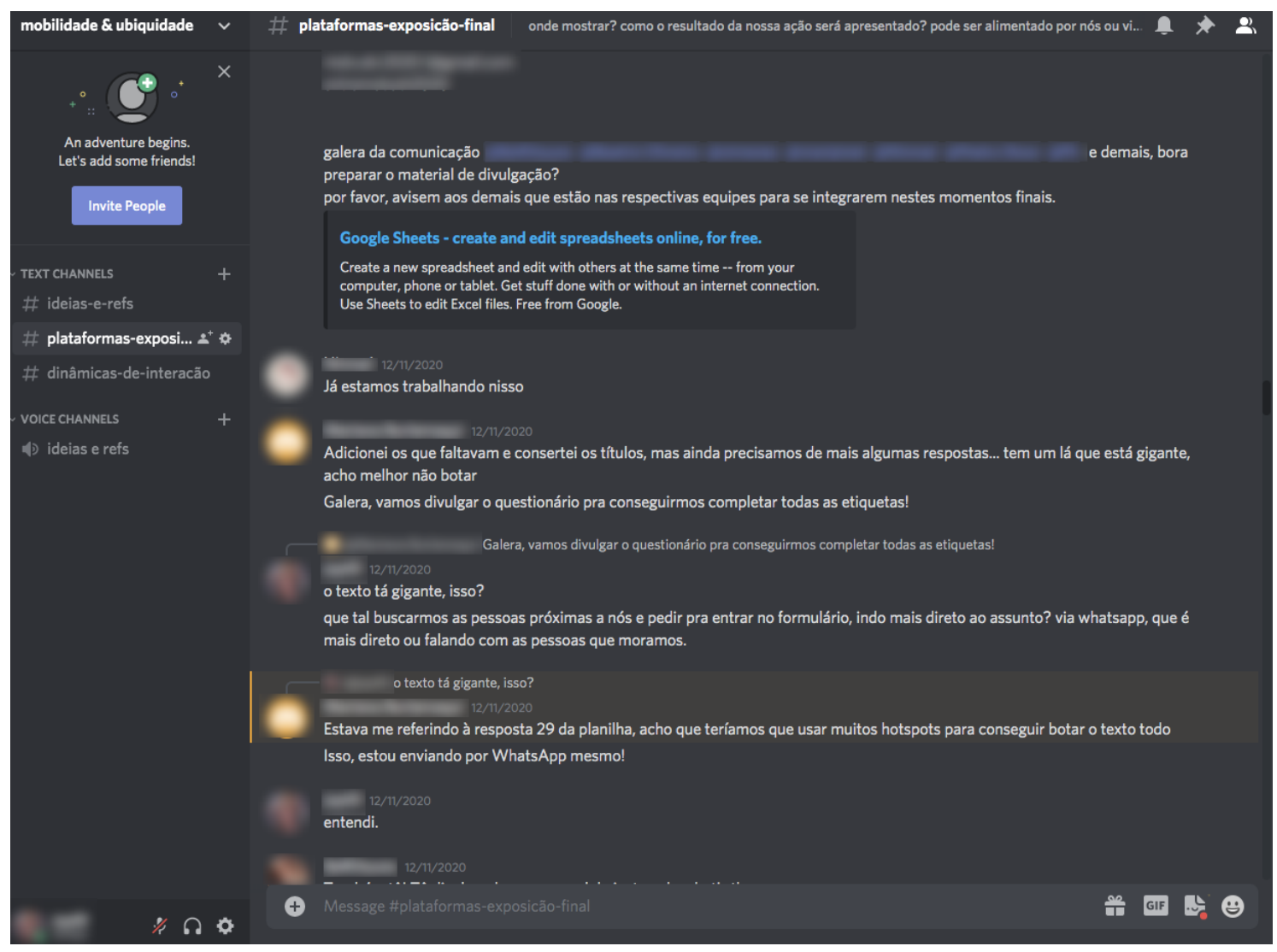

Muitos já conheciam a ferramenta e se sentiram bastante confortáveis com seu uso, outros se adaptaram sem maiores dificuldades, enquanto alguns alunos preferiram se comunicar apenas nos encontros semanais formais, desenvolvendo no tempo de aula suas tarefas e decisões com os colegas. Como alguns alunos apresentaram desconforto no uso de múltiplas redes de comunicação, se mostrando saturados com as solicitações constantes da vida on-line, o uso do Discord foi eletivo.

Para as comunicações oficiais, utilizamos o ambiente de ensino Classroom. A ferramenta, ainda que não possibilite tanto dinamismo na interação entre alunos e entre alunos e professores, se mostrou bastante adequada para a distribuição e avaliação de tarefas.

\section{A proposta implementada: "O que a pandemia Ihe fez valorizar?"}

Em 2020.2 não houve necessidade de debate entre temas: a pandemia e tudo que está no seu entorno reuniu as preocupações da turma. No entanto, fez-se necessário definirmos nosso olhar para a situação tão extraordinária vivida por todos. Angústia, ansiedade, insegurança, sofrimento etc, têm sido sentimentos presentes em maior ou menor grau, em boa parte da população mundial. Dentre diversas alternativas, decidimos pelo caminho de uma ação que provocasse a observação sobre os novos - ou desconhecidos - processos que foram sendo estabelecidos no cotidiano de cada um de nós. E que permitisse aos participantes expressarem o que a pandemia os fez valorizar. 
Diante do inesperado contexto surgido em março de 2020, pensamentos em torno de como mudamos nossa relação com a casa, com a universidade, ambiente e modo de trabalho, objetos etc, foram a base da pergunta norteadora da ação interativa: "O que a pandemia lhe fez valorizar?". Com o objetivo de representar a experiência de manifestação e inserção na rua, muito relevante na abordagem da disciplina, o conceito do trabalho foi a realização de uma obra de arte coletiva, como um grafite urbano, na qual os convidados participassem trazendo suas experiências, reflexões, sentimentos e ensinamentos sobre esse período de confinamento, de maneira livre, do modo que quisessem compartilhar.

Já havíamos explorado o Miro durante todo o semestre e percebemos que seu quadro branco, infinito em múltiplos zooms, poderia ser utilizado como uma espécie de parede/muro gigante, no qual todos que tivessem o link de acesso poderiam intervir com texto, desenho, fotos, links...

Também investigamos a ferramenta SuperViz ${ }^{7}$, que permite criar ambientes tridimensionais, nos quais navegamos no computador, em dispositivos móveis ou com óculos de realidade virtual. De manejo bastante fácil, pode ser alimentada com fotos panorâmicas e, dessa maneira, trazer a sensação de imersão em um ambiente. Explorando suas possibilidades, identificamos que poderíamos utilizar uma imagem panorâmica como fundo do cenário de navegação, o que nos permitia levar o grafite produzido anteriormente no Miro, recheado das falas e manifestações dos participantes.

Dessa maneira, para a construção da intervenção, definimos três etapas. Num primeiro momento, uma coleta de dados das respostas à pergunta norteadora, as quais posteriormente comporiam o ambiente final no SuperViz. Um segundo, composto por um evento que permitisse a produção coletiva e síncrona dos participantes, com alimentação de desenhos, textos, fotografias, vídeos, enfim, mídias diversas, potencializando a comunicação pelas mais diversas formas de expressão. E o terceiro, alimentado pelas duas fases anteriores e compondo o ambiente expositivo final: a obra de arte coletiva, publicada em uma plataforma on-line, que permitiria proporcionar a sensação de imersão em um lugar, através da tridimensionalidade.

Para tal, criamos e distribuímos um breve formulário para a comunidade da nossa universidade, no qual o participante enviava uma imagem e um pequeno texto descrevendo o porquê da sua escolha. Nosso objetivo era captar o que havia sido importante para cada um, algo que representasse um pouco do seu novo e imposto cotidiano.

\footnotetext{
${ }^{7}$ Superviz é uma ferramenta disponível on-line para criação e compartilhamento de ambientes 3D, nos quais podem ser inseridos vídeos, áudios, fotos etc, e receber visitas simultâneas de convidados. Com acesso via dispositivos móveis, computadores e óculos de realidade virtual, funciona direto no navegador. A empresa oferece um plano gratuito, adotado neste trabalho. <https://web.superviz.com/>
} 
Figura 3: Questionário simplificado divulgado nas redes sociais. Fonte: acervo dos autores.

\section{o que a pandemia te fez valorizar?}

A turma de Questões de Mobilidade e Ubiquidade da PUC-Rio quer saber de que objeto, algo ou alguém que você mais se aproximou nesses tempos de confinamento.

Desenhe ou tire uma foto e compartilhe conosco, contando um pouco do porquê da escolha.

Em breve, apresentaremos os resultados coletados, nos aguarde!

imagem

« Adicionar arquivo

porque foi (é) importante para você? *

Texto de resposta curta

De modo assíncrono, o banco de dados foi sendo construído com as contribuições enviadas durante algumas semanas, para posterior organização na exposição final.

Em outra frente, criamos um evento na plataforma Miro, elaboramos um convite para a data determinada e o divulgamos nas diversas mídias sociais. No horário estabelecido, um quadro branco, com uma imensa área para interação, foi disponibilizado aos participantes de modo que cada um pudesse fazer sua contribuição.

Figura 4: Convite via redes sociais para o grafite digital coletivo. Fonte: acervo dos autores.

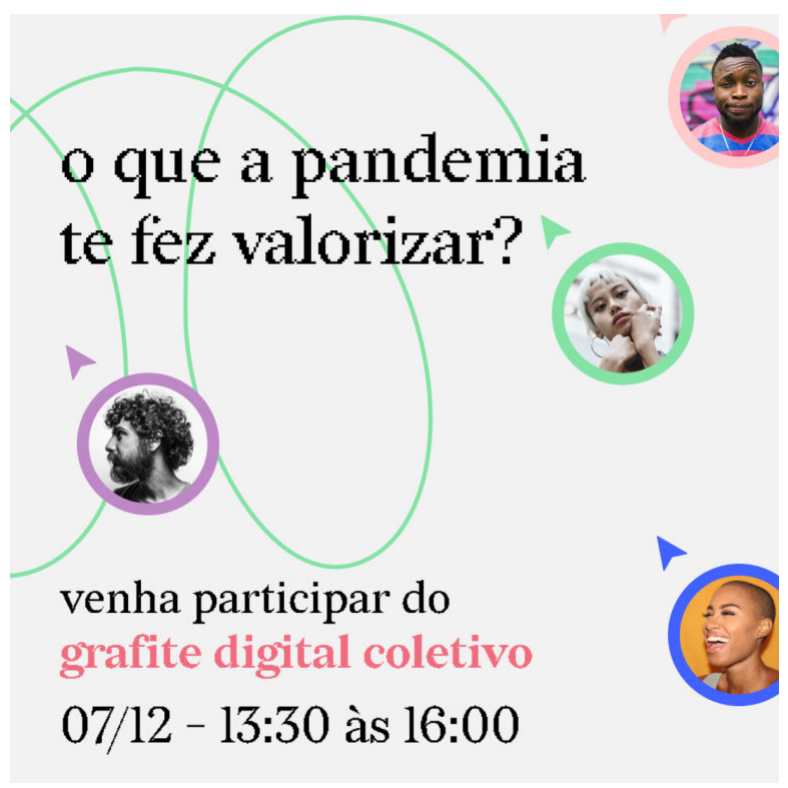

No decorrer da interação, os coparticipantes puderam explorar as diversas ferramentas que a plataforma Miro possibilita. Como o acesso se dava através do link $^{8}$ compartilhado durante a

\footnotetext{
${ }^{8}$ Disponível para visualização em <https://miro.com/app/board/o9J_ldZ9clE=/>
} 
divulgação, nenhum tipo de cadastro se fazia necessário. Dessa maneira, boa parte das colaborações se deu em modo anônimo, o que proporcionou uma maior liberdade aos participantes para contribuir com seus verdadeiros sentimentos e reflexões, sem maiores inibições.

Figura 5: Registro durante a ação coletiva. Fonte: acervo dos autores.

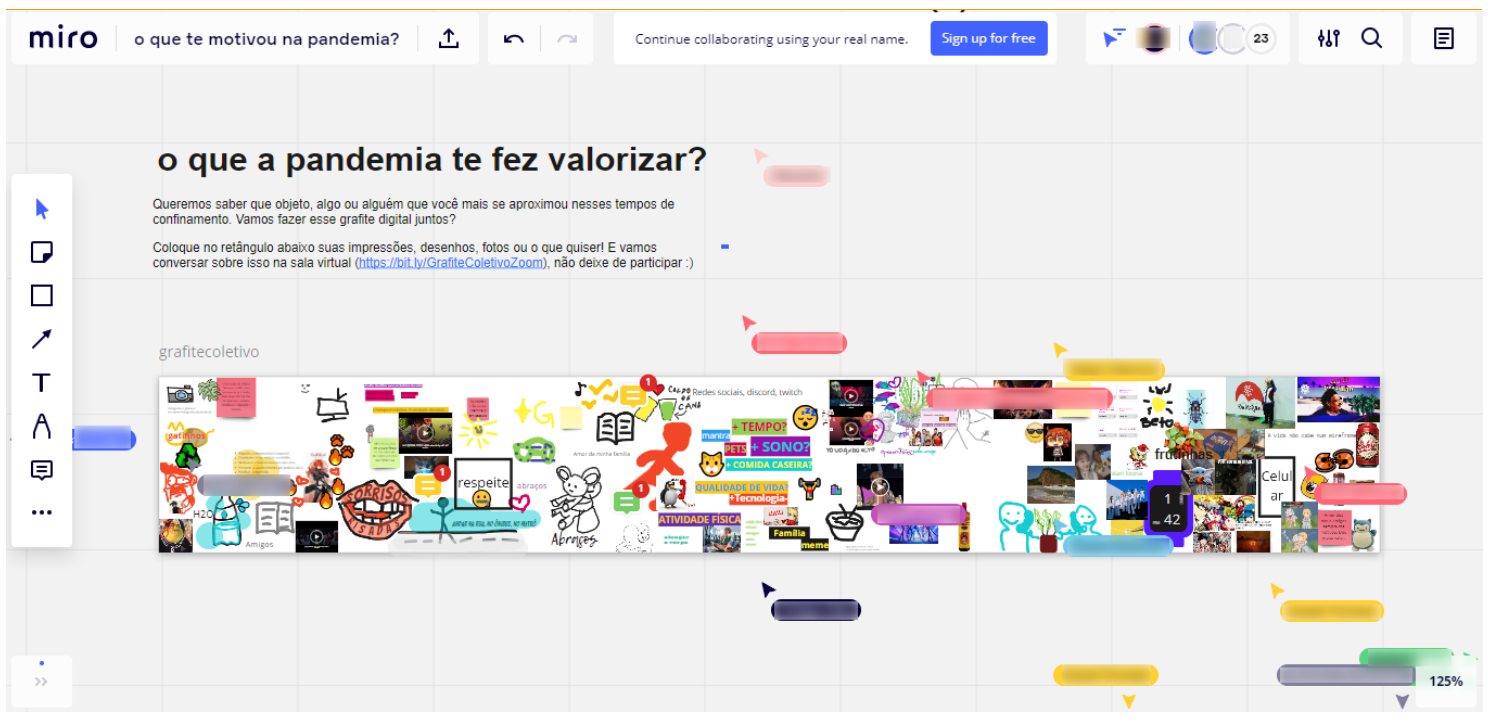

Figura 6: Imagem do painel ao final do evento. Fonte: acervo dos autores.

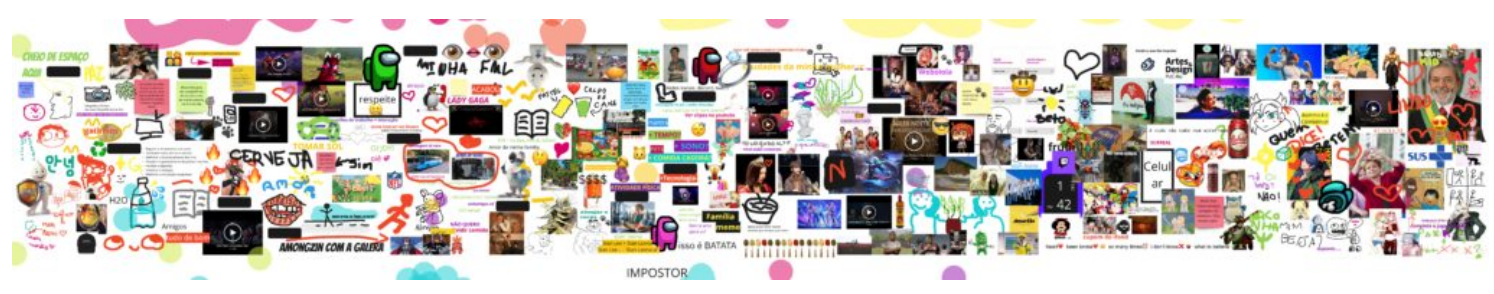

A terceira e última etapa da ação consistiu na exposição virtual coletiva, constituída pelas contribuições enviadas pelo formulário e pelo painel produzido no Miro. Todo o material foi levado para o SuperViz e, por meio desta plataforma, foi possível colocar o painel como plano de fundo e adicionar hotspots - pontos de interação no seu ambiente, tais como imagens, vídeos, documentos, textos, links - para aprofundar a navegação dos visitantes. Isso posto, o interator consegue explorar um ambiente tridimensional imersivo, e caso queira, ainda pode utilizar um óculos de realidade virtual para maior imersão naquele espaço. 
Figura 7: Convite vias redes sociais para o grafite digital coletivo. Fonte: acervo dos autores

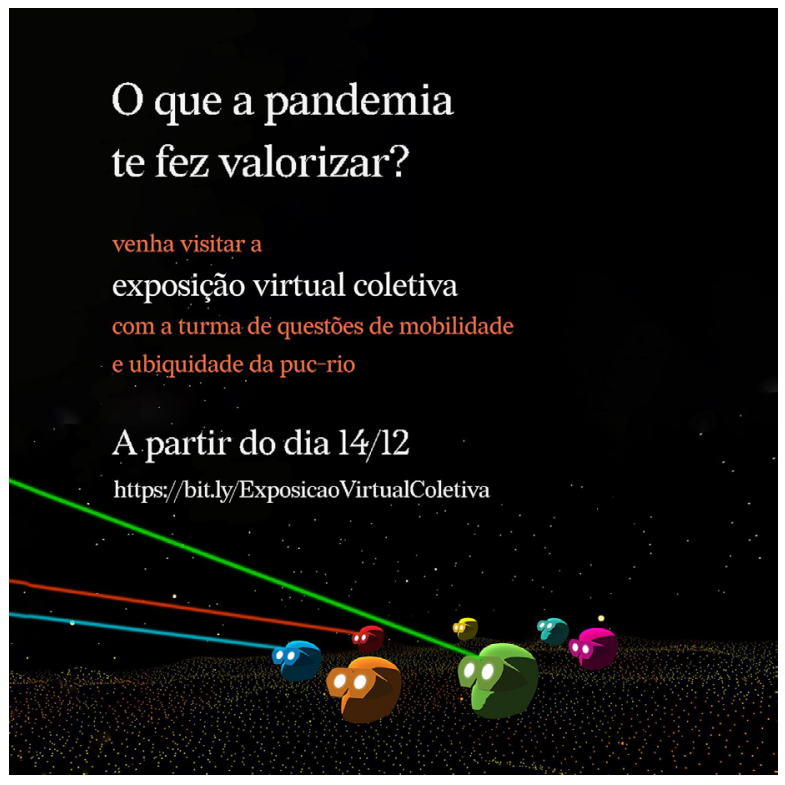

Diante desse contexto, a "parede" produzida no Miro se tornou o cenário do ambiente de visitação, enquanto as fotos e os textos coletados pelo formulário foram adicionados como hotspots. Criamos, assim, uma "exposição virtual coletiva" ${ }^{9}$, aberta ao público e também divulgada nas redes sociais. A exposição pode ser vista individualmente ou em grupos de até 8 pessoas, opção que possibilita aos visitantes simultâneos interagirem entre si por meio de vídeo e áudio.

Figura 8: Painel tridimensional final, já na plataforma SuperViz, com os hotspots direcionando para as imagens e textos enviados. Fonte: acervo dos autores.

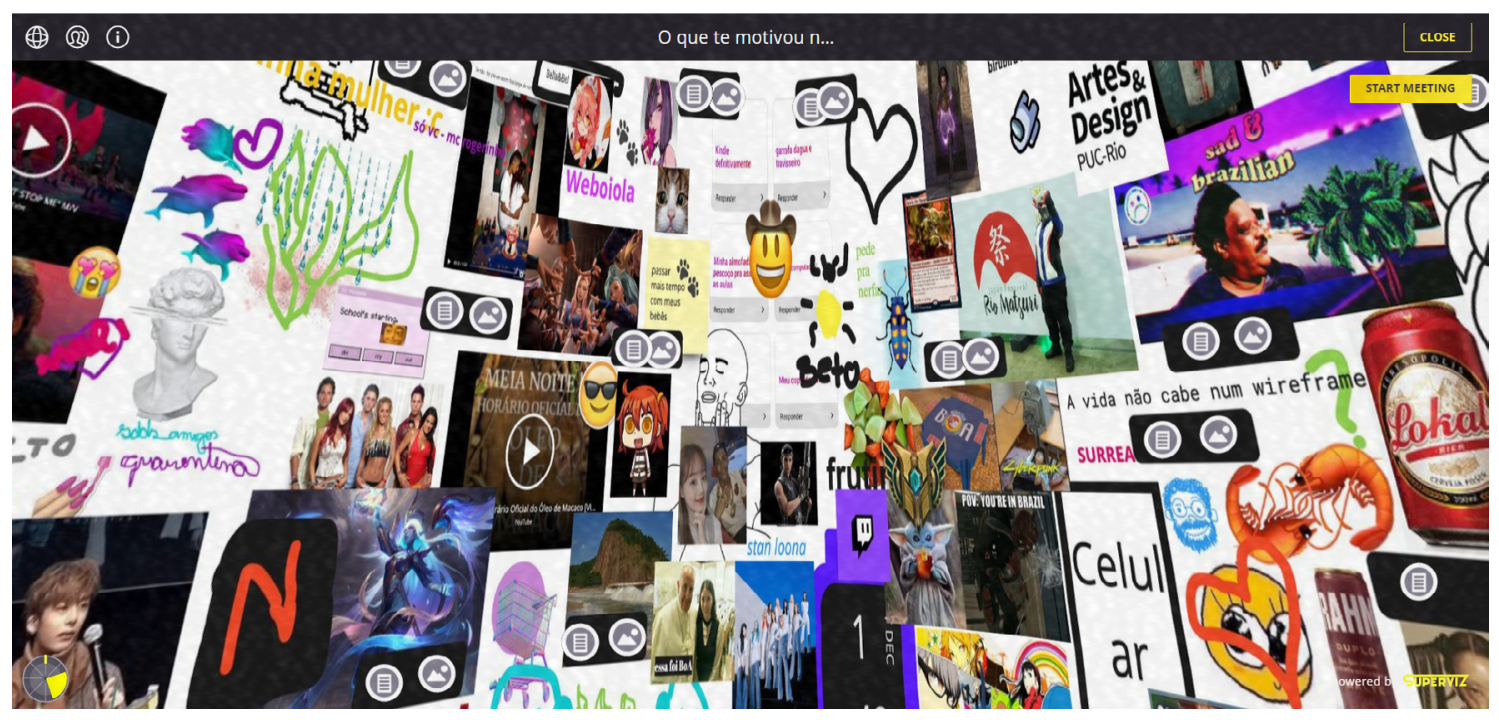

\footnotetext{
${ }^{9}$ A exposição permanece disponível no endereço: https://go.superviz.com/6a7cc2e448
} 
Figura 9: Detalhe de dois hotspots, resultados de uma colaboração do formulário.

Fonte: acervo dos autores.

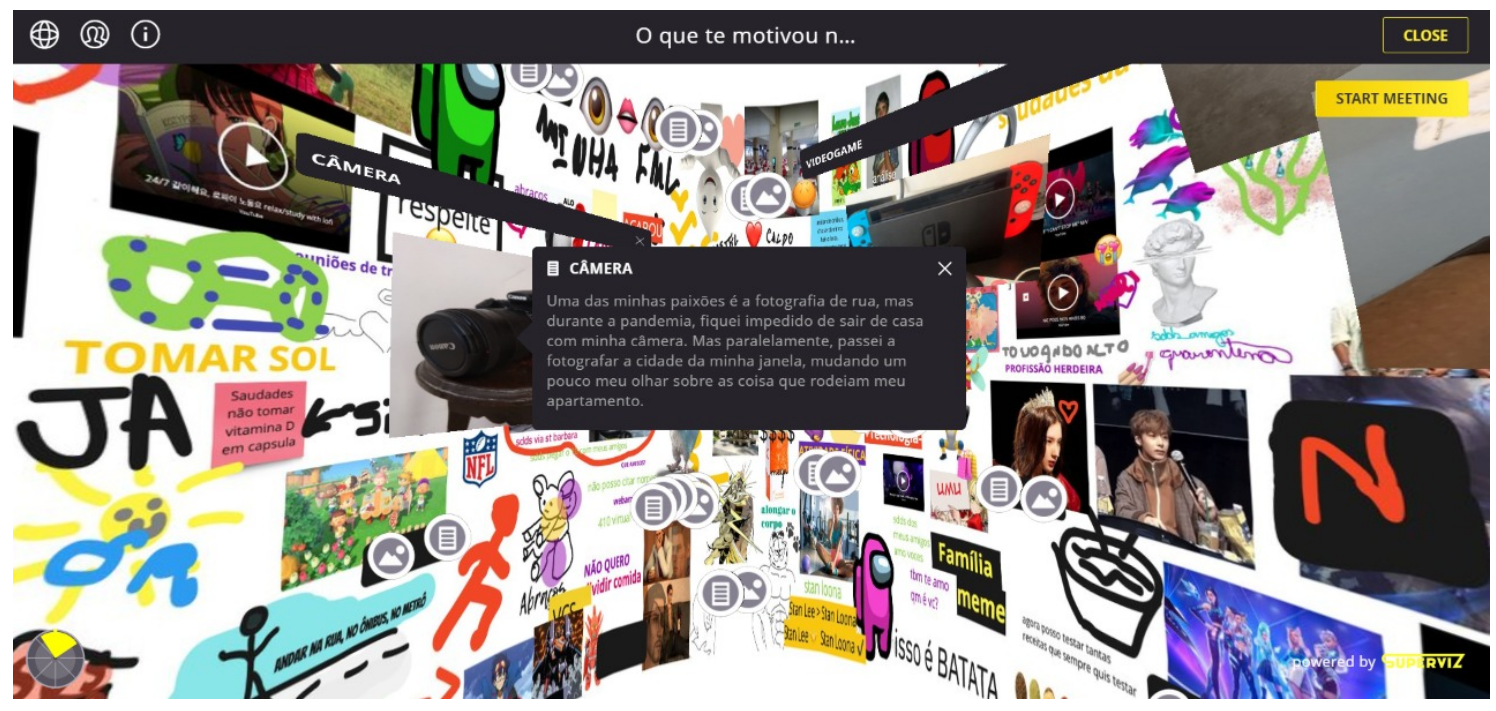

A exposição virtual permanece aberta aos visitantes, possibilitando uma memória coletiva das pessoas que participaram tanto pelo envio de referências relevantes para cada um, por meio do formulário assíncrono, como daqueles presentes na ação interativa do grafite digital, realizada colaborativamente.

Nos ricos registros da nossa vivência compartilhada neste período de confinamento, o conjunto das manifestações gráficas trouxe muitas formas de expressão: fotos, textos, ícones, emojis, ilustrações, diagramas, entre tantas, mas nitidamente o que mais se destacou foram os diversos memes, tão próprios da linguagem virtual contemporânea.

Ao final do semestre, avaliamos a ação em sala, refletindo sobre os objetivos alcançados e sobre o processo. $\mathrm{O}$ desenvolvimento de forma colaborativa, com atribuição de tarefas a cada pessoa da turma, não se deu de forma uniforme, com alguns alunos bem mais envolvidos do que outros. Porém, esta situação também ocorre em dinâmicas presenciais, não se distinguindo de experiências anteriores da disciplina. De qualquer modo, todos perceberam a importância da participação individual na construção coletiva, tendo tido o desafio de conceber, desenvolver e realizar a ação proposta somente no universo digital se configurando numa oportunidade de conhecer espaços e ferramentas virtuais.

\section{Reflexões finais}

Em pleno confinamento, trabalhando totalmente à distância, a turma concebeu e realizou uma obra de arte coletiva, na qual os convidados participaram trazendo suas experiências, reflexões, sentimentos e ensinamentos sobre esse momento, utilizando ferramentas disponíveis no ambiente da internet.

Por meio da atividade, propusemos aos participantes que fizessem uma análise pessoal de como o confinamento e a consequente mudança de hábitos os fez perceber os objetos cotidianos, e de que forma as relações com esses artefatos ganharam novos significados. Sob o 
enfoque do Design, buscamos trazer reflexões e estimulamos a exposição e o compartilhamento da mudança de olhar, adquirida durante a pandemia, para objetos e vivências cotidianas.

Diante das restrições do ensino remoto, a disciplina baseada na observação e análise das tecnologias relacionadas à mobilidade e à presença da computação em todos os campos de nossas vidas, neste semestre concentrou-se no espaço on-line. O mergulho em ferramentas e interações exclusivamente em rede teve como resultado um grande aprendizado de diferentes plataformas, configurando-se como uma relevante contribuição para o desenvolvimento de trabalhos futuros.

Ainda que o número de alunos que não utilizaram o Discord não tenha sido significativo, é importante observarmos que a convivência com tantas redes de comunicação intensamente entranhadas atualmente em nossas vidas, pode gerar sensações de saturação indesejadas. Se para alguns é mais confortável argumentar e conversar através de redes, outros conseguem participar durante as aulas e voltar a reencontrar a turma apenas neste espaço.

Durante este longo período de confinamento, infelizmente ainda em curso, mostrou-se muito clara a potencialidade do ambiente da internet, pleno de recursos que nos permitem ampliar dinâmicas de ensino-aprendizagem. Estas passam a se somar aos processos presenciais, abrindo caminhos ainda pouco explorados que apontam para modelos híbridos em um mundo cada vez mais interconectado. No entanto, ainda convivemos com muitas dificuldades de acesso a todo este universo virtual, questão a ser seriamente considerada em projetos semelhantes ao que apresentamos. Certamente, isto é algo que a pandemia nos fez enxergar e valorizar profundamente.

\section{Referências}

Joy Till Design. (2021). O que a pandemia Ihe fez valorizar? | 2020.2. Disponível em http://www.joytill.com.br/wp2017/2021/01/20/o-que-a-pandemia-te-fez-valorizar-2020-2/

Lévy, P. (2003). A inteligência coletiva: Por uma antropologia do ciberespaço (L. P. Rouanet, Trad.; $4^{\circ}$ ed). Edições Loyola.

Machado, Arlindo. O sujeito no ciberespaço. In: Intercom, XXIV Congresso Brasileiro da Comunicação. Disponível em http://www.portcom.intercom.org.br/pdfs/29708550691795394214029897104174778288.pdf. Campo Grande. Set. 2001.

Moran, J. M. (2002). Pedagogia integradora do presencial-virtual. São Paulo: Congresso Internacional de Educação à Distância. Disponível em http://www.abed.org.br/congresso2002/trabalhos/texto50.htm

Perrenoud, P. (2000). 10 novas competências para ensinar. Porto Alegre: Artmed.

Silva, M. (2001). Sala de aula interativa: a educação presencial e a distância em sintonia com a era digital e com a cidadania. Boletim Técnico Do Senac, 27(2), 42-49. Disponível em https://www.bts.senac.br/bts/article/view/567 


\section{Sobre os autores}

Joy Helena Worms Till, Dra., PUC-Rio, Brasil <falecom@joytill.com.br>

Rita Maria de Souza Couto, Dra., PUC-Rio, Brasil <rita7couto@gmail.com>

Julianna de Carvalho Lemos, Graduanda, PUC-Rio, Brasil <julemos2s@hotmail.com> 